\title{
How cross screw length influences the stiffness of intramedullary nail systems
}

\author{
S. V. Karuppiah ${ }^{1}$, A. J. Johnstone ${ }^{1}$, D. E. T. Shepherd ${ }^{2}$ \\ ${ }^{1}$ Orthopaedic Unit, Aberdeen Royal Infirmary, Aberdeen, UK; \\ ${ }^{2}$ School of Mechanical Engineering, University of Birmingham, Edgbaston, Birmingham, UK. \\ Email: saravanavail@yahoo.com
}

Received 25 October 2009; revised 20 November 2009; accepted 25 November 2009.

\begin{abstract}
Fractures of long bones are commonly treated with intramedullary (IM) nails and they have been shown to have a very high success rate. Recently we have concerns with the use of the newer IM nailing systems, that uses longer cross screws, which have been developed with variation in implant designs. We believe that the newer implants provide less fracture stability, due to decreased stiffness of the IM nailing system. The aim of this study was to biomechanically determine the influence of the length of cross screw on the stiffness of the IM nailing system, using a composite model. Our test results confirmed our suspicion that the newer IM nailing system using longer cross screw-length is less stiff than traditional nailing systems using shorter cross screw length, during axial loading.
\end{abstract}

Keywords: Intramedullary Nail; Mechanical Testing; Screw; Stiffness

\section{INTRODUCTION}

Orthopaedic implants have been popular in the management of fractures for the last six decades. There are various types of implants available for fixation of bone fractures, intramedullary (IM) nails being one of them. These are popular for the fixation of diaphyseal (shaft) fractures of the femur, tibia and humerus with high success rates. It is one of the accepted and most widely used methods of treating, transverse and short oblique, axially stable fractures of the femoral diaphysis $[1,2,3,4]$. It provides an excellent and prompt return of function with a low rate of complication and non-unions [5].

With the introduction of inter locking screws (cross screws) it has been also possible to provide rotational stability and precise reconstruction of the anatomy in communited fractures using the IM nailing system. The IM nailing system provide stiffness and stability of the bone segments, all factors which are considered to be essential preconditions for its increased success of bone union, while maintaining the function of the joints and soft tissues [6,7]. From time to time further changes in the design of the implant has been made, including the placement of the cross screws, to extend the use of femoral IM nails in all types of femoral fractures.

There is recent concern in our clinical practice regarding the use of newer femoral IM nailing system, using longer cross screw-length, designed to accommodate in extreme distal femoral metaphyseal fractures as compared to the traditional system which were designed to be used in diaphyseal fractures.

The anatomy of the human distal femoral bone is wider in diameter compared to the narrow diaphyseal bone. In order to accommodate the distal wider femoral bone fragment, the newer intramedullary nailing system uses longer cross screw-length that could be threaded from one cortex to the other.

The concept of stability is crucial in fracture surgery. Stability determines the amount of strain (i.e. relative change in fracture gap) at the fracture site, and strain determines the type of healing. Excessive strain could result in delayed or non-union of the fractures [8]. We believe that the longer cross screw-length, used in the newer IM nailing system, provides less stability to the fracture fixation due to decreased stiffness of the IM nailing system. The aim of this study was to determine the influence of the cross screw length on the stiffness of fracture fixation when using IM nailing systems.

\section{MATERIALS AND METHODS}

\subsection{Materials}

The intramedullary nails were simulated using stainless steel tubes with a length of $150 \mathrm{~mm}$, outside diameter of $12 \mathrm{~mm}$ and inside diameter of $10 \mathrm{~mm}$. These dimensions were similar to intramedullary nails used surgically. The distal hole in the intramedullary nail was $10 \mathrm{~mm}$ from the distal end. The distal bone end was simulated using stainless steel cylinders. In the study three different cylinders were used to represent different parts of the femur, with the dimensions comparable to clinical measure 


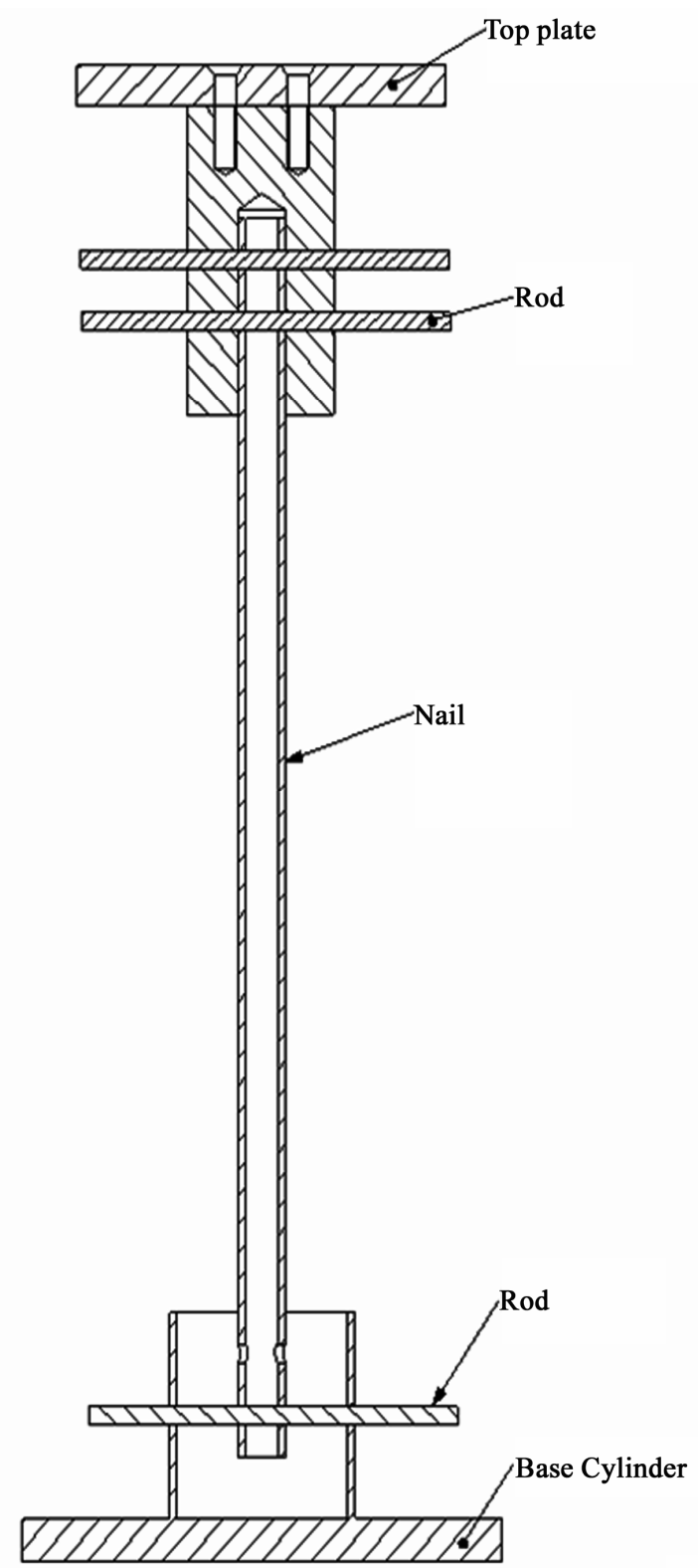

Figure 1. Test set-up.

ments using x-rays:

- outside diameter $50 \mathrm{~mm}$, wall thickness $5 \mathrm{~mm}$, height $50 \mathrm{~mm}$ (proximal diaphyses bone with a narrow canal and a thick cortical wall);

- outside diameter $75 \mathrm{~mm}$, wall thickness $3 \mathrm{~mm}$, height $50 \mathrm{~mm}$ (metaphyseal junction);

- outside diameter $100 \mathrm{~mm}$, wall thickness $3 \mathrm{~mm}$, height $50 \mathrm{~mm}$ (distal condylar bone with a wide canal and a thin cortical wall).

The hole in the cylinder was $25 \mathrm{~mm}$ from the top end of the cylinder.

\subsection{Methods}

An Instron 1822 materials testing machine (Instron Ltd.,
High Wycombe, UK) was used for mechanically testing the intramedullary nails. A customised stainless steel clamp was designed to connect the proximal portion of the intramedullary nail to the cross-head of the testing machine. The stainless steel cylinder, which represented the femur, was attached to the base of the testing machine. The distal end of the intramedullary nail was secured to the cylinders with a single stainless steel rod of diameter $5 \mathrm{~mm}$; this represented the cross screw. The test set-up is shown in (Figure 1).

The intramedullary nail was subjected to an axial compressive load, by lowering the cross-head of the testing machine; the load was applied at a rate of 0.05 $\mathrm{N} / \mathrm{s}$. During the testing load and displacement was re- 


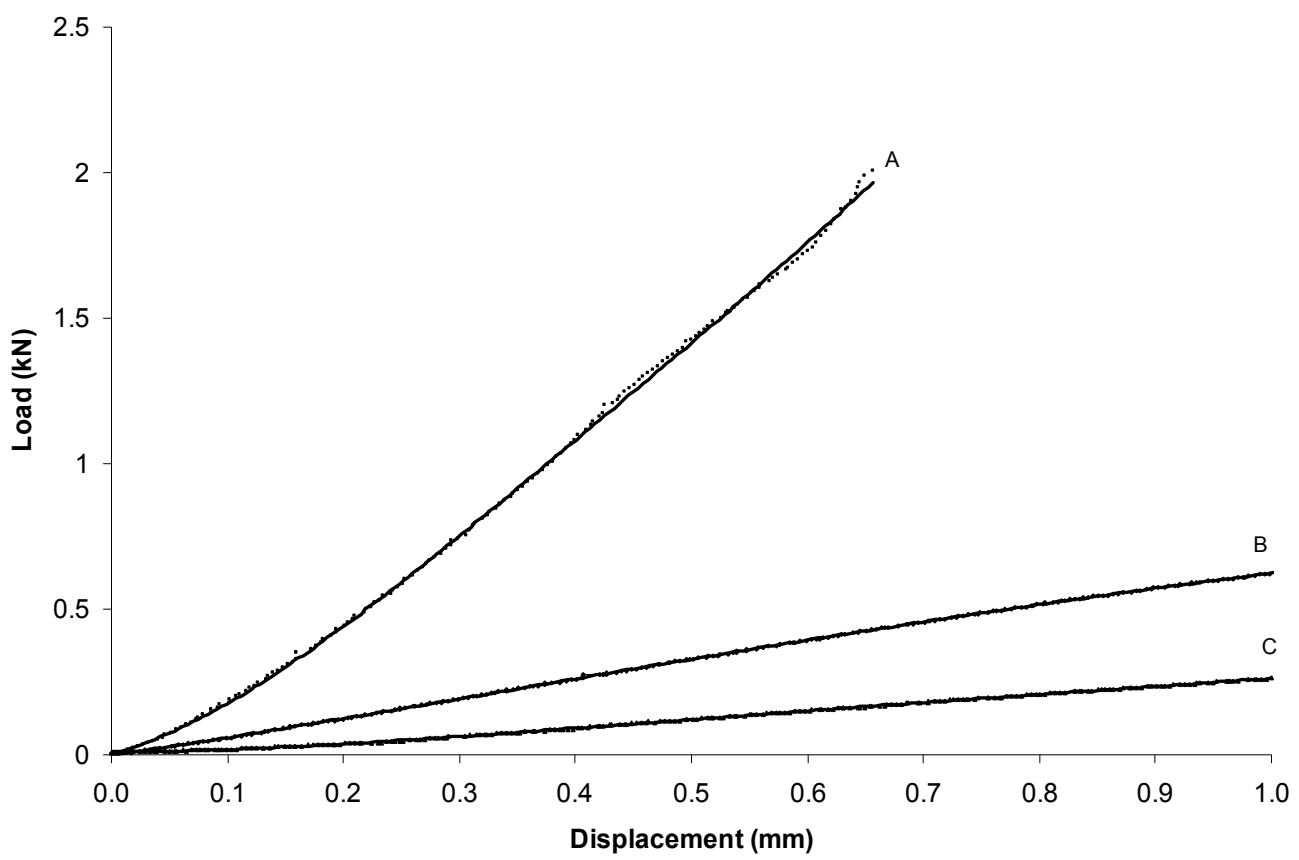

Figure 2. Graphs of load against displacement for a cylinder of outside diameter: A) $50 \mathrm{~mm}$. Curve fit $y=7.1293 x^{4}-11.956 x^{3}+7.7119 x^{2}+1.0647 x+0.0035, R^{2}=0.9995$; B) $75 \mathrm{~mm}$. Curve fit $y=0.1341 x^{4}-0.4407 x^{3}+0.3588 x^{2}+0.5726 x-0.0012, \quad R^{2}=0.9999 ;$ C) $100 \mathrm{~mm}$ Curve fit $y=$ $0.2709 x^{4}-0.7248 x^{3}+0.6727 x^{2}+0.0352 x+0.0091, R^{2}=0.9998$.

corded. Testing continued until a maximum displacement of $1 \mathrm{~mm}$ or the maximum force of $2 \mathrm{kN}$ was reached. A displacement of $1 \mathrm{~mm}$ was chosen; as the rod and the cylinder underwent mechanical deformation beyond $1 \mathrm{~mm}$. A load of $2 \mathrm{kN}$ represents about three times body weight for a $70 \mathrm{~kg}$ individual [9]. Each test configuration was tested three times.

Graphs of load against displacement were plotted (Figure 2 shows a typical example) and a forth-order polynomial fitted to the results. This polynomial fit enables us to use the same fit for all data. The stiffness was then determined from the gradient of the graph at a displacement of $0.5 \mathrm{~mm}$.

\section{RESULTS}

The mean stiffness of the intramedullary nail system decreases with increasing diameter of the cylinder, which represents the femoral bone. The mean $( \pm$ standard deviation) stiffness of the system was $3298 \pm 144$ $\mathrm{N} / \mathrm{mm}, 657 \pm 10 \mathrm{~N} / \mathrm{mm}$ and $297 \pm 16 \mathrm{~N} / \mathrm{mm}$ at diameters of $50 \mathrm{~mm}, 75 \mathrm{~mm}$ and $100 \mathrm{~mm}$, respectively.

\section{DISCUSSION}

The principle aim of fracture fixation is to provide stability of the bone fragments and restoration of normal anatomy. Intramedullary nails act as a scaffold and are devised to hold together the proximal and distal ends of the long bone for a conducive environment for fracture healing. The placement of the cross screw and the design of the implant can influence the stability of fracture fixation and hence bone union $[10,11]$.

The proximal (diaphyseal) femoral canal is narrow in which the intramedullary nail has a 'snug fit' against the bone. Hence, the inter bone-nail distance is minimal or none. In the current study it has been shown that with this set-up it has a mean stiffness of $3298 \mathrm{~N} / \mathrm{mm}$. With increasing bone diameter, the stiffness of the system decreases, leading to an increased deflection for a given load. At the distal condylar part of the femur, there is a wide canal and a thin cortex. The distance of the cross screw from the bone is increased in this case.

In the clinical situation, when the patient bears weight the greater the diameter of the canal, the greater the deflection will be. As shown in this experiment, there is a proportionate decrease in axial stiffness of the intramedullary nail with increasing cross screw-length. Longer cross screw-length, used in the newer intramedullary nailing system to treat distal femoral fractures, will be far less stiff during weight bearing than the traditional IM nailing system, which uses shorter cross screwlengths. The newer IM nails hence provide less stability of fracture fixation and may potentially cause delayed union or non-union when used to treat femoral fractures.

\section{REFERENCES}

[1] Wolinsky, P.R., McCarty, E., Shyr, Y. and Johnson, K. (1999) Reamed intramedullary nailing of the femur: 551 cases. Journal of Trauma-Injury Infec- 
tion \& Critical Care, 46, 392-399.

[2] Wiss, D.A. and Stetson, W.B. (1995) Unstable fractures of the tibia treated with a reamed intramedullary interlocking nail. Clinical Orthopaedics \& Related Research, 56-63.

[3] Rommens, P.M, Verbruggen, J. and Broos, P.L. (1995) Retrograde locked nailing of humeral shaft fractures. A review of 39 patients. see comment. Journal of Bone \& Joint Surgery - British Volume, 77, 84-89.

[4] Bick, E.M. (1968) The intramedullary nailing of fractures by G. Kuntscher. Translation of article in Archiv fur Klinische Chirurgie. Clinical Orthopaedics \& Related Research, 60, 5-12.

[5] Schatzker, J. (1998) Fractures of the distal femur revisited. Clinical Orthopaedics \& Related Research, 43-56.

[6] Brumback, R.J., Toal, T.R., Murphy-Zane, M.S., Novak, V.P. and Belkoff, S.M. (1999) Immediate weight-bearing after treatment of a comminuted fracture of the femoral shaft with a statically locked intramedullary nail. Journal of Bone \& Joint Surgery-Am, 81, 1538-1544.

[7] Hente, R., Fuchtmeier, B., Schlegel, U., Ernstberger, A. and Perren, S.M. (2004) The influence of cyclic compression and distraction on the healing of experimental tibial fracture. Journal of Orthopaedic Research, 22, 709-715

[8] Taylor, S.J., Walker, P.S., Perry, J.S., Cannon, S.R. and Woledge, R. (1998) The forces in the distal femur and the knee during walking and other activities measured by telemetry. J.Arthroplasty, 13, 428-437.

[9] Schandelmaier, P., Farouk, O., Krettek, C., Reimers, N., Mannss, J. and Tscherne, H. (2000) Biomechanics of femoral interlocking nails. Injury, 31, 437-443.

[10] Henley, M.B., Meier, M. and Tencer, A.F. (1993) Influences of some design parameters on the biomechanics of the unreamed tibial intramedullary nail. J Orthop Trauma, 7, 311-319. 